Discussion Paper No. 633

TRADE REFORMS, DEFORESTATION AND INDUSTRIAL POLLUTION IN DEVELOPING COUNTRIES:

ONE SIZE DOES NOT FIT ALL

\author{
Ian Coxhead \\ and \\ Sisira Jayasuriya
}

March 2005

The Institute of Social and Economic Research Osaka University

6-1 Mihogaoka, Ibaraki, Osaka 567-0047, Japan 


\title{
Trade Reforms, Deforestation and Industrial Pollution in Developing Countries: One Size Does Not Fit All ${ }^{*}$
}

\author{
Ian Coxhead \\ Department of Agricultural and Applied Economics \\ University of Wisconsin, Madison \\ 413 Taylor Hall, 427 Lorch St \\ Madison, WI 53706, USA \\ coxhead@wisc.edu \\ Sisira Jayasuriya \\ Faculty of Economics and Commerce \\ University of Melbourne \\ Parkville, VIC, Australia \\ skj@unimelb.edu.au
}

\footnotetext{
* This is a revision of University of Wisconsin-Madison, Department of Agricultural and Applied Economics Staff Paper Series No. 462 (Revised, January, 2004). The authors would like to thank Max Corden, Bayou Demeke, Charles Horioka, Yoshiyasu Ono, Peter Warr, participants at the European Association of Environmental and Resource Economists annual congress (Bilbao, Spain; June 2003), and seminar participants at the Melbourne University, UC-Berkeley, UC-Davis, Osaka University, and the University of Wisconsin for helpful comments on earlier drafts. Remaining errors are ours alone.
} 


\section{Trade Reforms, Deforestation and Industrial Pollution in Developing Countries: One Size Does Not Fit All}

Many developing countries possess comparative advantage both in natural resources and in labor-intensive industries, and experience both industrial pollution and natural resource degradation. We present a model that incorporates these stylized facts together with key spatial features and property rights failures typical of developing economies. We explore consequences of anticipated domestic and global trade policy and world price changes. Similar exogenous or policy shocks are seen to have contrasting effects, depending on initial economic structure, trade orientation and policy regime. Further, when there is more than one sectoral source of environmental damage, a policy or price change may have unexpected environmental and welfare results. Nevertheless, in many empirically important cases, reducing protection for capital intensive manufactures is likely to improve both income and environmental quality, a point that we illustrate by reference to some Asian case studies. These results stand in contrast to those obtained in much of the current analytical literature.

Key Words: Trade, environment, pollution, deforestation, developing countries.

JEL: F18, O24, Q28 


\section{Introduction}

Developing countries increasingly face problems of air and water pollution arising from industrial emissions, in addition to degradation of natural resources such as forest, land and water. Though they may occur in different sectors, different types of environmental degradation are not independent: in addition to bio-physical relationships, they are also linked by sectoral interdependencies operating through factor and commodity markets. This means that strategies for alleviating environmental degradation must take account of these linkages.

This need is of particular importance in analyses of the relationship between trade and the environment. By the 1990s, the benefits of liberalized trade for economic development had won widespread acceptance, motivating trade policy reforms in most developing countries. More recently, however, concerns about environmental consequences of freer trade have reignited the trade liberalization debate. The value of a better understanding of trade-environment links in the specific context of developing economies is now very high. Sectoral interdependencies demand that this relationship be approached from a general equilibrium perspective.

Although general equilibrium theoretical approaches to trade-environment questions are well established, the current literature in this area has serious limitations where developing economies are concerned. On environmental issues, many analyses are highly aggregative, combining widely different types of environmental damage into a single variable. Though this approach can help elucidate basic principles, it is much less useful as a guide to normative analysis and policy formulation. Other analyses choose to deal only with a single concern, such as air pollution or deforestation. Even in their excellent review of key literature and consolidation of main analytical results, Copeland and Taylor (2003) deliberately restrict the scope of their analysis to industrial pollution, omitting analysis of natural resource use and 
depletion. ${ }^{1}$ While the focus on industrial pollutants may arguably be adequate for some industrialized economies, it is inadequate for developing countries, where natural resource degradation shares top billing or even outranks industrial pollution as a leading environmental problem (Asian Development Bank 1997; Jha and Whalley 1999). Nowhere is this more true than in tropical Asia, where natural resource stocks are under severe threat, with deforestation rates the highest of any world region (Table 1).

For the past three decades, the fundamental rationale for trade policy liberalization in developing countries has been the recognition of multiple sources of comparative advantage, emphasizing their potential for export success not only in natural resource products, but also in labor-intensive manufactures (Little et al 1970; Bhagwati 1978; Papageorgiou et al 1991; Collier and Gunning 1994). Though this literature is silent on the environmental consequences of trade, any policy-relevant analysis of trade-environment questions cannot afford to ignore its central insight on comparative advantage, highlighting the critical importance of labor intensive exports for economic growth.

The seminal formalization of the links between manufacturing sector trade reforms and natural resource degradation in a developing country setting is Deacon (1995). He analyzes the impact of tariff reform on deforestation in a Ricardian model with two traded goods (a protected, import competing manufactured good and an exportable agricultural good) and one intersectorally mobile factor, labor. Labor is also used to convert open-access forest into agricultural land. Trade liberalization shrinks the manufacturing sector, which releases labor. This reduces the cost of forest conversion for agriculture, thereby unambiguously increasing deforestation. This illustrates the proposition that an institutional failure, a particular type of distortion of which open access to a natural resource is one example, will lead to socially 
excessive pollution (or resource degradation) when trade frictions are reduced, if the country has comparative advantage in the polluting sector (Brander and Taylor 1997). At the same time, however, this result pits environmental concerns against the conventional gains from trade liberalization; if preservation of the natural environment has positive value, then the Deacon result indicates a welfare tradeoff.

This tradeoff, however, is contingent on a model structure that precludes by assumption the more realistic case in which a developing country also has comparative advantage in some labor-intensive manufacturing industry. In addition, the model assumes that there is no welfarereducing industrial pollution. In fact, empirical evidence indicates that capital-intensive heavy industry - the sector typically protected - is much more pollution-intensive than are laborintensive industries (Table 2 illustrates this point). As we will show in this paper, the implication of an unambiguously negative relationship between trade liberalization and environmental quality that emerges from the Deacon model, as with the Brander and Taylor result on reducing trade frictions, does not hold robustly in models that are consistent with the key stylized facts of developing countries.

In the following section we set out a model which retains the key institutional assumption of weak property rights in natural resources, but in which there is scope for more diversified production structures both in manufacturing and in natural resources sectors. We show that while there may in principle be a tradeoff between industrial pollution and natural resource degradation, in the most empirically relevant cases lowering manufacturing sector protection is likely to reduce both industrial pollution and natural resource degradation. We also explore likely implications for developing countries of some other important trade-related shocks and policy reforms, including those anticipated in the current Doha Round negotiations. Our results 
highlight the sensitivity of outcomes to differences in economic structure and the need for caution when generalizing about the environmental effects of trade reforms and price shocks; because relevant aspects of economic structure vary even among apparently similar developing countries, one size does not fit all.

\section{Model structure and assumptions}

As indicated, our model attempts to capture key stylized features of small developing economies, particularly those in tropical Asia, though many of its features are common to many other developing countries. $^{2}$ In particular, we model a small open economy with comparative advantage in two types of good, an agricultural commodity and labor-intensive manufacturing. The model comprises two sub-economies, manufacturing and agriculture. We make the following initial assumptions:

1. Manufacturing $(M)$ is a mini-Heckscher-Ohlin economy with mobile labor and capital, producing an import-competing, tariff-protected good $H$, and an exportable $X . X$ has a relatively high labor-to-capital ratio $(\ell)$. Based on empirical evidence on the relative pollution intensity of industries in developing countries, we specify that the low $\ell$ sector is pollution-intensive ('dirty'), while the other sector is 'clean'. Industrial emissions, $J$, are produced in constant proportion to the output of $H$, i.e. $J=\beta y^{H}, \beta>0$. The external costs of pollution are not internalized by dirty sector firms.

2. Agriculture $(A)$ is a mini-Ricardo-Viner-Jones economy, in which the sectors are distinct sub-regions, 'upland' $(U)$ and 'lowland' $(F)$ with region-specific endowments of land, $T$ in upland and $N$ in lowland. $T$ and $N$ differ due to variation in elevation, soil type, access to irrigation and other agro-climatic factors. Labor is mobile between the two sectors. 
Initially we assume that the lowland region produces import-competing 'food', whereas the upland produces plantation crops for export, as is typical in many tropical countries. ${ }^{3}$ This regional division reflects the important stylized fact that in much of the tropics, rice and other staple foods are grown primarily in river deltas and other low-lying, often irrigated areas, while 'uplands' or 'dry lands' are often planted to a mix of crops that may include food alongside perennial crops such as tea, rubber, cacao and oil palm. Conversion of 'uplands' to 'lowlands' is thus very costly, and differences in key agroclimatic factors result in continuing productivity differences that justify treating these as essentially two different land types. The outer boundary of upland cultivation in the tropics is usually the forest frontier; the conversion of forest land to agriculture is essentially an upland phenomenon. ${ }^{4}$

3. Forest is an open-access resource that yields $T$ through deforestation. To focus on the environmental benefits of forest we assume it to produce only non-marketed outputs. ${ }^{5} T$ is produced and maintained using labor $L^{T}$ according to $T=L^{T} / \alpha$, where $\alpha>0$ is the unit labor requirement. Thus the labor available for upland agricultural production is $L^{U}-\alpha T$. We also assume that labor $(L)$ is freely mobile among all activities and sectors; there are constant returns to scale, complete markets (except for environmental goods) and perfect competition in goods and factor markets. Consumers derive utility from consumption of marketed goods and environmental goods (standing forest and clean air). Environmental phenomena affect the economy only through consumer utility rather than through intersectoral effects on production costs, and we ignore trans-boundary pollution issues. ${ }^{6}$ Finally, to focus on the environmental stories we assume that tariff and tax revenues are redistributed to consumers in lump-sum fashion. We recognize that trade liberalization does have important dynamic growth 
effects, and thereby contributes to what Antweiler et al. (2001) have termed the 'scale effect' (a bigger economy pollutes more, other things equal). However, our focus is on changes in the structure of production and factor demand, or the 'composition effect' of trade-related changes derived via comparative static analyses. $^{7}$

The foregoing assumptions mean that we have an economy with three distortions: a tariff in the import-competing manufacturing sector, an absence of property rights in forests, and a missing market for pollution produced by firms in manufacturing. In principle, first-best policies would imply moving to free trade while imposing Pigovian taxes on polluting firms, and enacting appropriate reforms to ensure that forest-related consumption externalities are fully internalized. But analytical issues arise precisely because in practice, such first best policies are very difficult to implement. Hence it is appropriate to explore the effects of specific policy reforms in the continuing presence of one or more of these distortions.

Turning to the model, full employment of labor implies $L=L^{U}+L^{F}+L^{M}$. Prices for each good are denoted by $p^{U}$ and $p^{F}$ for upland and lowland agriculture respectively, and $p^{H}$ and $p^{X}$ (= 1 by assumption) respectively for the import-competing (dirty) and exportable (clean) manufactures. We assume these prices to be set in world markets and thus to be exogenous to the economy. The quantities of lowland land and manufacturing capital $(K)$ are assumed exogenously fixed, but there is an endogenous supply of upland land through deforestation. Using this notation and assuming profit-maximizing producers, we define maximum revenue functions for each sector or region:
Lowland (food): $\quad Q\left(L^{F}, N, p^{F}\right)$
Upland: $\quad R\left(L^{U}-\alpha T, T, p^{U}\right)$ 
Manufacturing: $\quad S\left(L-L^{F}-L^{U}, K, p^{H}\right)$.

These functions reflect profit maximization subject to endowment constraints and are nondecreasing and homogeneous of degree 1 in prices and endowments. Their sum is equal to total value added, $I$ :

$$
I=Q\left(L^{F}, N, p^{F}\right)+R\left(L^{U}-\alpha T, T, p^{U}\right)+S\left(L-L^{F}-L^{U}, K, p^{H}\right)
$$

We capture consumer preferences and behavior with a conditional minimum expenditure function, in which the quantity of industrial emissions, $J$, and the area of standing forest cleared for agriculture, $T$, are exogenous to the consumer. Letting $\mathbf{p}$ stand for the vector $\left(p^{F}, p^{U}, p^{H}, 1\right)$ :

$$
E=E(\mathbf{p}, J, T, v)
$$

This embodies all the information on the preferences of a utility-maximizing representative consumer with utility function $v(F, U, H, X ; J, T)$, with $v_{j}>0$ for all $j \in(F, U, H, X), v_{J} \leq 0, v_{T} \leq$ 0. We follow existing trade models in assuming utility to be separable between marketed goods and environmental goods.

Let subscripts on $Q, R, S$, and $E$ indicate derivatives of these functions with respect to subscripted variables, for example $R_{T}=\partial R / \partial T$. To reduce notational clutter we write derivatives with respect to sectoral prices using sectoral symbols, for example, $E_{M}=\partial E / \partial p^{H}, E_{H F}=$ $\partial^{2} E / \partial p^{H} \partial p^{F}$, and so on. By the properties of the revenue and expenditure functions and the envelope theorem, $R_{U}$ is the supply of upland output, $Q_{N}$ is the shadow value of lowland, $E_{H}$ is domestic demand for import-competing manufactures, $E_{T}$ is the negative of willingness to pay for standing forest, $E_{v}$ is the reciprocal of the marginal utility of income, and so on. Finally, recall that the initial domestic price of $H$ is increased by a tariff; this is given by $t^{H}=p^{H}-\bar{p}^{H}$, where $\bar{p}^{H}$ is the world price in domestic currency terms. 
Given return of tax revenues to consumers in lump-sum form, the aggregate budget constraint of this economy is:

$$
E=I+t^{H}\left(E_{H}-S_{H}\right)
$$

There is full employment in equilibrium, so the usual marginal productivity condition for labor requires that the following conditions hold:

$$
\begin{aligned}
& Q_{L}\left(L^{F}, N, p^{F}\right)=R_{L}\left(L^{U}-\alpha T, T, p^{U}\right) \\
& R_{L}\left(L^{U}-\alpha T, T, p^{U}\right)=S_{L}\left(L-L^{F}-L^{U}, K, p^{H}\right) \\
& R_{T}\left(L^{U}-\alpha T, T, p^{U}\right)-\alpha R_{L}\left(L^{U}-\alpha T, T, p^{U}\right)=0
\end{aligned}
$$

Conditions (4) and (5) state that in equilibrium, the marginal product of labor is equal in value terms across all sectors. Condition (6) ensures that within the upland sector, labor used in land clearing and in production are of equal value at the margin. It is thus a property of the model that since labor is the only input to land clearing, any shock that raises labor productivity in upland production also generates pressures for deforestation. ${ }^{8}$ The solution to equations (3) to (6) yields equilibrium values of real income, $L^{F}, L^{U}$, and $T$, each as a function of $\left(\mathbf{p}, t^{H}, L, N, K\right)$. From these we can calculate changes in $L^{M}$ as well as sectoral and regional outputs, the wage, and industrial emissions. So long as production of land from forest is a linear function of labor alone, however, we can obtain all the comparative static results of interest by solving (5) and (6) for $L^{F}$ and $L^{U}$. The solution will then yield $L^{M}$ from the labor constraint, and $T$ can be found directly from $L^{U}$. For price changes, comparative static results are obtained by totally differentiating (4) and (5), holding all factor endowments except land constant, to yield: 


$$
\left[\begin{array}{cc}
Q_{L L} & -R_{L L} \\
S_{L L} & \left(R_{L L}+S_{L L}\right)
\end{array}\right]\left[\begin{array}{l}
d L^{F} \\
d L^{U}
\end{array}\right]=\left[\begin{array}{c}
-Q_{L F} d p^{F}+R_{L U} d p^{U} \\
S_{L H} d p^{H}-R_{L U} d p^{U}
\end{array}\right],
$$

in which $|\Delta|$, the determinant of the coefficient matrix, is quickly established as $Q_{L L}\left(R_{L L}+S_{L L}\right)+R_{L L} S_{L L}>0$. Comparative static results are obtained using Cramer's rule.

\section{Environmental and welfare effects of trade policy reforms}

In this section we use the model first to see the effects of domestic trade policy reforms. WTO compliance by developing countries typically requires reduced manufacturing sector protection, so we stylize this reform as a manufacturing tariff reduction (the agricultural tariff case will be explored later in the paper). Subsequently, we examine potential changes in international prices reflecting the relaxation of rich-country cereal export subsidies as envisaged under the Doha Round, then a counterpart shock affecting world demand for tropical industrial crops, which are mainly grown in the areas we have described as 'upland'.

\section{Effects of domestic tariff reform}

In this model, a price shock in one sector alters economy-wide resource allocations, and so affects the production of each type of environmental damage, with economy-wide labor mobility, and capital mobility within manufacturing, serving as adjustment mechanisms. Consider first a tariff reform. A ceteris paribus tariff reduction in the capital-intensive manufacturing sector raises the return to labor and causes out-migration of workers from agriculture. Solving from (7), using the definition of $t^{H}$ and setting $d t^{H}<0$ gives:

$$
d L^{F}=\frac{1}{\Delta} R_{L L} S_{L H} d t^{H}<0
$$




$$
d L^{U}=\frac{1}{\Delta} Q_{L L} S_{L H} d t^{H}<0
$$

By substitution into the full employment constraint (with $d L=0$ ) we also find:

$$
d L^{M}=-\frac{1}{\Delta} S_{L H}\left(Q_{L L}+R_{L L}\right) d t^{H}>0,
$$

Tariff reduction, by raising labor productivity in manufacturing relative to that (measured at initial wages) in other sectors, results in labor migration to manufacturing from agriculture. This leads to the following proposition concerning environmental damages:

Proposition 1 (Tariff reform): Reducing the tariff on the polluting manufacturing sector reduces deforestation and reduces industrial pollution when the protected manufacturing sector is relatively pollution-intensive, and increases overall welfare.

Because $H$ is capital-intensive, reducing its relative price causes $X$ to expand, driving up wages. The drop in $H$ output results in lower emissions, i.e. $d J<0$. Labor moves out of agricultural sectors, and since $d T / d L^{U}=\alpha>0$, deforestation declines. It is thus a feature of the model that even with comparative advantage in plantation crops and open access to forested land for conversion into plantation crop land, the plantation sector contracts when the tariff on an importcompeting sector is reduced.

The real income effect of a small change in the tariff is found by totally differentiating (3), using (2) and (1) and setting changes in the exogenous prices and quantities equal to zero. Defining net imports $Z_{H}=\left(E_{H}-S_{H}\right)$, and using (4) - (6) to eliminate some terms, we obtain:

$$
\gamma d v+E_{J} d J+E_{T} d T=t^{H} Z_{H H} d t^{H}-t^{H} S_{H L} d L^{M}
$$


where $\gamma=E_{v}-t^{H} E_{H v}>0$ and $d L^{M}=-\left(d L^{F}+d L^{U}\right)$. The first term on the left hand side provides the usual measure of change in the real consumer income; the second and third terms capture the utility effects of changes in environmental variables. If we ignore these for a moment by setting $E_{J}=E_{T}=0$, then (11) provides a measure of real income change due to the tariff change. The first term on the right hand side conveys the familiar deadweight loss of protection due to reallocation of resources within the manufacturing sector. Since $Z_{H H}=\left(E_{H H}-S_{H H}\right)<0$, this term is positive for $d t^{H}<0$. The second term captures an additional efficiency change due to the reallocation of labor between manufacturing and agriculture. For a tariff reduction this signed term is also positive. In sum, real income must increase when trade is liberalized. Finally, we know that both $d T<0$ and $d J<0$ for a tariff reduction, so if $E_{J} \leq 0$ and $E_{T} \leq 0$, a broad measure of consumer welfare, consisting of the sum of all three terms on the left hand side of (11), is unambiguously increased by trade reform. ${ }^{9}$

\section{Effects of global market shocks}

The Doha round of world trade talks includes proposals for the major industrialized food exporters to reduce subsidies paid to their own farmers. These measures, if implemented, would raise world prices of most agricultural products - especially cereal grains. Wheat and feedgrain prices are predicted to rise by about $25 \%$; rice and corn by $8-12 \%$, and oilseeds by $8 \%$ (Dimaranan et al. 2002). Global trade reforms could thus impose large terms of trade shocks on food-trading developing economies. This motivates our second experiment, in which we examine the effects of a rise in global grain prices.

By the same method as in the tariff change analysis, the labor market effects of an increase in the price of food, the lowland agricultural product $\left(d p^{F}>0\right)$ are: 


$$
\begin{aligned}
& d L^{F}=-\frac{1}{\Delta}\left(Q_{L F}\left(R_{L L}+S_{L L}\right)\right) d p^{F}>0 \\
& d L^{U}=\frac{1}{\Delta} Q_{L F} S_{L L} d p^{F}<0 \\
& d L^{M}=\frac{1}{\Delta} Q_{L F} R_{L L} d p^{F}<0 .
\end{aligned}
$$

The food price rise causes labor to migrate out of uplands and manufacturing. In our model, lowland agriculture is a 'clean' industry producing import-competing goods. A first reaction would be to predict a real income loss offset by gains from reduced environmental damage. The story, however, is not so neat.

Proposition 2 (food price rise): A rise in the world price of import-competing food crops, with labor mobile across all sectors and capital mobile within manufacturing, reduces real income and deforestation but increases industrial pollution. Welfare gains are theoretically ambiguous.

The labor market response shown in (12) to (14) is clear. It can readily be deduced that the price shock results in a contraction of upland production, so $d T<0$. In manufacturing, however, less labor means lower output in the clean sector and thus, with a fixed capital stock, more in the dirty sector, so $d J>0$. In this model the projected grain price increases from the Doha Round will have positive net environmental effects only if the benefits of lower upland production and reduced deforestation exceed the costs of increased pollution from expansion of 'dirty' capital intensive manufactures.

The real income effect of the rise in $p^{F}$ is given by:

$$
\gamma d v+E_{J} d J+E_{T} d T=-Z_{F} d p^{F}+t^{H}\left(E_{H F} d p^{F}-S_{H L} d L^{M}\right)
$$


For $t^{H}$ taking small values, a rise in $p^{F}$ has a direct real income effect in which consumer losses are proportional to food imports. This first-order effect is modified by two second-order effects capturing, respectively, higher tariff revenues due to substitution in consumption between $F$ and $H$, and in manufacturing, an increase in tariff-related losses due to the expansion of $H$ and contraction of $X$. The first of these offsets part of the first-order real income loss while the second causes additional losses. Real income net of environmental effects thus declines while industrial pollution increases. Hence overall welfare, inclusive of environmental changes, can increase only if the gains from reduced deforestation outweigh combined losses in real income and higher industrial pollution. Empirically, a gain is possible only if $E_{J} d J$ and the effects of food price rises are very small, while utility gains from reduced deforestation are very large.

The second global price shock experiment concerns exportable agricultural products, which we assume (for now) to be grown in uplands only. Global demand for tropical plantation commodities such as rubber, oil palm and timber is expanding rapidly, in large part because of the continuing rapid growth of large developing economies such as China and India. What will be the net environmental and welfare effects a global boom in upland crop prices?

For an increase in the upland commodity price $\left(\mathrm{dp}^{\mathrm{U}}>0\right)$ we obtain labor market responses as:

$$
\begin{aligned}
& d L^{F}=\frac{1}{\Delta} R_{L U} S_{L L} d p^{U}<0 \\
& d L^{U}=-\frac{1}{\Delta} R_{L U}\left(Q_{L L}+S_{L L}\right) d p^{U}>0 \\
& d L^{M}=\frac{1}{\Delta} R_{L U} Q_{L L} d p^{F}<0 .
\end{aligned}
$$

These results provide an indication of the likely direction of output changes, and motivate proposition 3. 
Proposition 3 (Plantation crop price rise): An increase in the price of plantation crops grown in uplands, with labor mobile across all sectors and capital mobile within manufacturing, increases real income but also increases both forms of environmental damage. Welfare gains are more likely the lower the value attached to environmental damages.

Raising the upland price produces a positive real income effect through the terms of trade, but unambiguously increases deforestation as upland agriculture expands, through in-migration of labor. But this is only the direct environmental impact. Less obviously, intersectoral migration also contributes to an increase in industrial pollution. At constant relative prices of manufactures, reducing the labor endowment of manufacturing as a whole causes $X$ to contract, drawing capital and labor into $H$; thus, the dirty sector expands and the clean sector contracts.

To find welfare effects, take the total differential of (3) with respect to $p^{U}$, holding the tariff, factor endowments and other product prices constant:

$$
\gamma d v+E_{J} d J+E_{T} d T=-Z_{U} d p^{U}+t^{H}\left(E_{H U} d p^{U}-S_{H L} d L^{M}\right)
$$

The symmetry with the food price case is clear. For an exportable, domestic excess demand $Z_{U}<$ 0, so the first expression on the r.h.s is a positive direct terms of trade effect which raises real income. Indirectly, the price change causes both expenditure and $M$ sector resources to switch toward $H$. As before, these second-order effects have opposed signs, so their net effect must be small in relation to the first-order impact through $Z^{U}$. The environmental losses are clear: $d T$ is positive (i.e. deforestation increases), reflecting the higher value of open-access upland, and the transfer of $M$ sector resources into $H$ makes manufacturing more emissions-intensive, i.e. $d J>0$. 
Welfare will rise only if environmental losses, weighted by their utility valuations, are smaller than the real income gain.

This case if of particular interest to resource-abundant developing economies. Higher global demand for industrial plantation crops such as oil palm and rubber produce income gains for major exporters, such as Indonesia, but they come at a substantial environmental cost in terms of the deforestation. ${ }^{10}$

No additional calculations are needed in order to see that the joint effects of global price shocks affecting both categories of agricultural product will be ambiguous: real income may rise or fall, and pressures on forests may increase or decline. The only definite outcome is that as agricultural prices rise, industrial pollution will also rise as withdrawal of labor from manufacturing, with a fixed capital stock, causes the labor-intensive industry to contract and the capital-intensive industry to expand. Deforestation will rise or fall, depending on the extent to which manufacturing releases labor and on the relative magnitudes of the labor demand effects from lowland and upland agricultural price changes. In a nutshell, country-specific environmental consequences of global agricultural trade policies depend on initial economic structure.

\section{Structural effects: a geometric illustration}

The intuition underlying the above analyses can be appreciated with a geometric model. In Figure 1 the central panel (b) shows the economy-wide labor market. The width of the panel denotes the economy's total labor endowment; employment in agriculture is measured to the right from $0_{A}$, and that in manufacturing to the left from $0_{M}$. Labor demand curves for the $M$ and A sub-economies are constructed by horizontal addition of those for the respective sectors, as 
shown. In the initial equilibrium, the economy-wide wage $(w)$ is given by the intersection of $L_{A}$ and $L_{M}$.

The right-hand panel (c) shows unit cost (i.e. zero profit) curves for each manufacturing sector in factor price space (Mussa 1979). Note that the wage is set economy-wide, rather than purely within the manufacturing sector. Product prices and the wage determine the set of feasible manufacturing industries and the location of their unit cost curves. The (negative of the) aggregate capital-labor ratio in manufacturing is shown by the line $\ell \ell^{\prime}$; an increase in the ratio increases the slope of this line, and a ratio higher than the slope of a line tangent to $c_{H}$ at the intersection of the unit cost curves (point $G$ ) implies specialization in capital-intensive production. ${ }^{11}$ For given wage and prices, with both goods being produced, we can read off the equilibrium return to $M$ sector capital, $r_{M}$, on the horizontal axis.

In the left-hand panel (a) we show the analogous curves for the two agricultural sectors. The horizontal axis shows unit returns to land in each agricultural region, $r_{U}$ and $r_{F}$. These are not required to be equal, though for convenience we have chosen units of land so as to equate them in the initial equilibrium.

Weak property rights in uplands means that profit-maximizing producers use this resource up to the point at which its average product is equal to average cost (Gordon 1954). We can capture this by interpreting the curve $L_{A}$ in panel (b) as the horizontal sum of labor demands in lowland and upland agriculture, noting that under open access to forests, upland labor demand exceeds the quantity that would be observed if property rights were enforced. In the initial equilibrium, open access means that there is overuse of labor in upland; were property rights enforced, the total labor demand curve in agriculture would lie to the left of $L_{A}$. 
In manufacturing, because we assume that producers in the dirty industry are not penalized for emissions, free disposal of air and water pollutants leaves producers on their (private) marginal product curves, while producing a negative social externality.

To illustrate the working of the model, let the labor-intensive manufacture, $X$, be the numéraire good and set $p^{X}=1$. Consider the example of an increase in the price of upland agriculture, $p^{U}$. As shown in panel (b) of Figure 2, this displaces the demand for upland labor vertically upwards by the amount of the price rise, and aggregate agricultural labor demand curve is increased by the price change times the upland share of agricultural labor. With no change in manufacturing prices, labor is withdrawn from manufacturing and moves into agriculture; within agriculture, it is reallocated from lowland to upland production.

As a result of the price change, production in upland agriculture rises and that in lowland falls. For the lowland, where the quantity of land is fixed, the output change is proportional to the reduction in labor use at the new, higher wage. For the upland, we suppose that new land may be brought into production; however, as long as the labor required for forest conversion is directly proportional to that required for upland production, the change is still proportional to the corresponding labor demand shift. Returns to land in each agricultural region are altered, as seen in panel (a); that in upland must rise, and that in lowland fall.

At the original wage and price levels, the withdrawal of labor from $M$ has predictable resource allocation effects. The aggregate labor-capital ratio in manufacturing falls (in terms of Figure 1, the line $\ell \ell^{\prime}$ becomes steeper) and the labor-intensive sector contracts, while $H$ expands. This is not an equilibrium, however, as the increase in upland labor demand also exerts upward pressure on the wage. With constant output prices, the productivity of labor in $M$ must rise to match the wage increase. As a consequence of the wage increase the $M$ sector's aggregate labor 
demand falls and the $L_{M}$ curve in panel (b) moves to the right. The final labor market equilibrium, depending on the extent to which the $M$ industries in aggregate release labor, will be an economy-wide labor allocation lying between $L^{1}$ and $L^{2}$, with a wage between $w^{0}$ and $w^{1}$. In manufacturing, both the quantity and price effects of the economy-wide labor market adjustment reduce the output of the labor-intensive sector; the output of the capital-intensive sector may rise or fall. The return on $M$ sector capital must also fall.

The environmental effects of the agricultural price increase can be inferred from the diagram. In manufacturing, dirty output has expanded relative to clean, so the overall emissionsintensity of manufacturing has risen. Whether total emissions rise or fall depends on whether or not the dirty sector has expanded in absolute terms. The price rise for upland raises the return to labor used in clearing forest along with that of labor used in production. Looking across the economy as a whole, the price rise is an environmental lose-lose outcome (more deforestation, more emissions) if $H$ expands, or a lose-win outcome if $H$ contracts.

The geometric exposition again highlights the observation that when there is more than one source of environmental damage, and when these are associated with activities in distinct sectors of the economy, the net effects of a policy or price shock may differ from its direct sectoral effect. It may confer an environmental benefit in the directly affected sector, but may indirectly confer a benefit or a loss in another sector. This point is not captured in models where 'environmental damage' refers to a single phenomenon such as forest loss or industrial pollution.

\section{Effects of domestic agricultural trade reforms}

Many developing countries are net food importers and protect domestic food sectors. WTO agreements, among other influences, have led many, such as China, India, Indonesia and Sri 
Lanka to relax agricultural protection over the past decade. What are the environmental consequences of such reforms?

We can adopt the previous approach, with minor modifications, to analyze this case. For greater policy relevance, in this exercise, we also relax Assumption 2, that food is produced only in the lowland, and suppose that both regions grow food crops that are substitutes (e.g., rice and corn), and that production is sold in competition with imports in a tariff-protected domestic market. This better fits the stylized facts of food-importing countries (see next section).

Redefining the domestic price vector so $\mathbf{p}=\left(\bar{p}^{F}+t^{F}, \bar{p}^{U}+t^{U}, \bar{p}^{H}+t^{H}, 1\right)$, the aggregate budget constraint is rewritten as $E=I+\mathfrak{t}^{\mathbf{}} \mathbf{Z}$, where $\mathbf{t}^{\mathbf{}} \mathbf{Z}$ is the inner product of the tariff vector and the vector of excess demands for $F, U$ and $H$. From (4) and (5), the labor market impacts of tariff reforms in agriculture follow by substitution of tariff changes for price changes. The aggregate budget constraint, ignoring variables held constant at their initial values, is:

$$
E(\mathbf{t}, J, T, \mathrm{v})=Q\left(L^{F}, t^{F}\right)+R\left(L^{U}, T, t^{U}\right)+S\left(L^{M}, t^{H}\right)+\mathbf{t}^{\prime} \mathbf{Z}_{\mathbf{j}}
$$

for $j \in(F, U, H)$. Then the effects of changes in $t^{F}$ and/or $t^{U}$ are again found by total differentiation. The results differ from terms-of-trade shocks by the absence of first-order welfare effects and presence of second-order terms capturing tariff distortions and the extent to which output in each sector responds to a labor endowment change.

Proposition 4 (Agricultural trade liberalization): In food-importing countries, lowering protection on food crops reduces industrial pollution, and may also reduce deforestation.

Taking the total differential with respect to the agricultural tariffs gives: 


$$
\begin{array}{r}
E_{v}\left(1-\mathbf{t}^{\prime} \mathbf{E}_{\mathbf{j v}}\right) d v+E_{J} d J+E_{T} d T=\mathbf{t}^{\prime} \mathbf{Z}_{j j} d t^{j}+\left(t^{H} S_{L L}-t^{F} Q_{L F}\right) d L^{F} \\
+\left(t^{H} S_{L L}-t^{U} R_{L U}\right) d L^{U}
\end{array}
$$

In this expression, the first term on the r.h.s. is the standard real income loss due to an increase in a tariff, and is negative (positive) for $d t^{j}>(<) 0$. The other two terms within parentheses are both non-positive, so the overall sign depends on changes in $L^{F}$ and $L^{U}$. Solving for changes in labor demand due to tariff reductions, analogously to the procedure shown in (7) to (10), gives $d L^{F} / d t^{F}<0, d L^{U} / d t^{F}>0, d L^{M} / d t^{F}>0$, and $d L^{F} / d t^{U}>0, d L^{U} / d t^{U}<0, d L^{M} / d t^{U}>0$. Hence the prediction of aggregate real income change (with $E_{J}=E_{T}=0$ ) is indeterminate. By the same logic used earlier, the environmental consequences are $d T / d t^{F}>0, d J / d t^{F}<0$ for a reduction in $t^{F}$, and $d T / d t^{U}<0, d J / d t^{F}<0$ for a reduction in $t^{U}$. Lowering the tariff on the lowland food crop increases deforestation but reduces industrial pollution, while lowering that on the upland food crop reduces both. If the two occur together, industrial pollution will unambiguously diminish, but the deforestation rate may rise or fall. The following table summarizes these results.

\begin{tabular}{llll} 
& \multicolumn{3}{c}{ Tariff change } \\
\cline { 2 - 4 } & $d t^{F}<0$ & $d t^{U}<0$ & Both \\
\hline$d L^{F}$ & $<0$ & $>0$ & $?$ \\
$d L^{U}$ & $>0$ & $<0$ & $?$ \\
$d L^{M}$ & $>0$ & $>0$ & $>0$ \\
$d J$ & $<0$ & $<0$ & $<0$ \\
$d T$ & $>0$ & $<0$ & $?$ \\
\hline
\end{tabular}


Tariff reduction in upland agriculture yields conventional real income gains, and reduces both forms of environmental damage - a win-win outcome. Lowland agricultural tariff reduction may increase deforestation but is otherwise economically and environmentally desirable. ${ }^{12}$

\section{Strengthening upland property rights}

The open access nature of property rights in the forest sector leads to overexploitation of forests, and establishing well-defined property rights is an important element of the institutional reform agenda in developing countries. Though space limitations preclude presenting the formal analysis, the economic reasoning is clear. Recall from the discussion of Figure 1 that because there is open access to forests for conversion to upland land, the privately optimal labor allocation in upland agriculture equates average, rather than marginal costs and returns. Thus the curve $L_{A}$ in panel (b) of the figure is equal to the horizontal sum of labor's value marginal product in lowland agriculture and its average product in upland. It follows that enforcing property rights in forests, which reduces the rents earned from land-clearing, displaces the $L_{A}$ curve to the left-in the limiting case, when property rights in forest are fully enforced, to the point at which it is simply the sum of the upland and lowland marginal (i.e. labor demand) curves. In panel (c), increased labor availability to lowlands and lower economy-wide wage will once more reduce the overall emissions-intensity of manufacturing production. Thus the establishment of property rights in forestland will tend to reduce both deforestation and urban pollution in this case, even though forestlands will continue to remain undervalued as long as their full environmental benefits are not reflected in their land values.

\section{Economic structure and environment: some stylized Asian economies}

The core model outlined in section 2 is capable of a number of permutations, each reflecting a different economic structure and set of policies. It can be easily adapted, for example, to model a 
range of cases in developing Asia, where countries such as Indonesia, Malaysia, Philippines, Sri Lanka, Thailand and Vietnam provide a laboratory of sorts for the comparative study of the interaction of growth, trade, policy reforms, and environment. Despite many similarities, they differ in terms of some key aspects of economic structure (Table 3). Some, for example, are important food exporters (Thailand and Vietnam) while others are net importers and typically protect their food sectors (Philippines, Indonesia). All, however, face common problems in terms of rising industrial pollution, deforestation and other forms of natural resource degradation.

Until the 1990s most countries maintained high protection for import competing capitalintensive manufactures, with outcomes strongly consistent with the discussion above. Protection raised profitability of capital intensive manufactures, discouraged labor-intensive exports, and made the manufacturing sector as a whole more emissions-intensive. Because the tariff lowered returns to labor in manufacturing, labor moved into agriculture, reduced the cost of land-clearing for upland agriculture, and increased deforestation. This has been a common story throughout tropical Asia. But contrasting outcomes emerge when the effects of agricultural trade policies are examined.

In the Philippines, a net food importer, food is cultivated in both lowlands and uplands, with rice in the lowlands and corn in the uplands. Its policy of food sector protection draws labor out of manufacturing, and as the model showed, the labor-intensive, export-oriented manufacturing industry experiences the largest relative output decline. Both upland and lowland agriculture expand. Lowland, however, is constrained by a fixed land endowment; in uplands, the higher food price increases the return to forest clearing to create new lands. Thus the protection for food producers increases deforestation and reduces the output of labor-intensive manufactures. The emissions-intensity of manufactures rises, but overall industrial pollution 
may rise or fall since the sector as a whole will contract. The combination of industrial protection and agricultural protection in this type of economy thus favors both emissionsintensive industrial development and deforestation at the upland agricultural margin. By the same token, liberalization of both agricultural and manufacturing trade is likely to have positive income and environmental effects. ${ }^{13}$

In contrast, Indonesia's upland agriculture produces primarily industrial crops for export. Protection for lowland agriculture (food), in this economy, causes the lowland region to expand, raising labor demand; this promotes down-slope migration and discourages deforestation at the upland frontier. As before, the protection for food producers also draws labor out of the manufacturing sector, reducing the relative size of the clean exportable goods sector and increasing emissions-intensity. By comparison with the first example, in this case food sector protectionism tends to diminish pressures on forests. Hence, in Indonesia's case, the real income gains that will accrue from liberalization of food imports has to be balanced against increased deforestation. Thailand and Vietnam, whose lowland agriculture produce an export crop (rice) present yet another variant, with different income and environmental outcomes associated with trade policy reforms and exogenous price movements. Global reductions in food prices, for example, may well cause increased deforestation as labor moves out of lowland agriculture, in addition to the negative income effects associated with terms of trade declines.

These brief sketches indicate ways in which apparently minor variations in economic structure can be associated with significantly different income and environmental outcomes in response to similar policy shocks or exogenous changes. If nothing else, they do indicate clearly that even within a relatively similar subset of developing economies, there are no grounds for supposing the existence of a common set of environmental and natural resource depletion trends 
in the course of economic growth. Further, generalizations about the income and environmental outcomes of domestic or international policy reforms for developing countries may be quite misleading.

\section{Conclusions}

Debate on the environmental effects of trade liberalization in developing countries remains intense, but available models often miss significant structural features critical to policy relevant analysis. Our analysis in this paper highlights, first, the need to recognize that it may be misleading to focus on only some types of environmental damage when considering the overall impact on environmental degradation. Different types of environmental damage-in our example, industrial emissions and deforestation-respond in different ways to economic shocks, requiring calculation of the relative economic value of different types of environmental resources and the net economic value of the overall environmental effects. Second, the actual environmental outcomes of specific exogenous shocks or policies depend critically on the initial structure of the economy. The same shock could well have opposed environmental effects in two developing economies that appear very similar in many respects. This finding undermines the generality of findings on the trade-environment relationship that rely on more abstract characterizations of economic structure. Third, in yet another illustration of the theory of second best, when environmental externalities coexist with policy-induced distortions, partial policy liberalization may have negative effects on aggregate welfare or on environmental problems. However, from a policy standpoint, it should be stressed that the widespread opposition to trade liberalization among many environmentalists may be misplaced: because most developing countries have intrinsic comparative advantage in labor intensive products, liberalization of 
manufacturing imports is likely to improve both (conventionally measured) real incomes and environmental quality in many developing countries.

None of these findings are novel to trade theorists, but they have yet to emerge as clearly understood facets of economy-environment relationships in developing economies. These analytical results can also play an important role in highlighting the limitations of reliance on oversimplified or over-general models in the trade-environment literature.

The model we have presented can be extended to address other important issues, such as the impact of international capital flows into developing economies. It can also more explicitly incorporate various types of intersectoral production externalities and issues related to internal market segmentation in factor and goods markets. ${ }^{14}$ In addition, the model provides guidance for construction of more richly specified applied general equilibrium analyses of the environmental outcomes of policy and global market shocks. It should be emphasized, however, that trade policies cannot substitute for targeted environmental policies, partly (but not only) because scale effects of growth are likely to dwarf composition effects in the longer run. On the other hand, that it is equally important to recognize that domestic and global trade policy liberalization is not always anti-environment. Indeed, in a number of developing countries, trade liberalization may not only confer conventional income gains, but be pro-environment as well. 


\section{References}

Antweiler, W., B. R. Copeland, and M. S. Taylor, 2001. "Is free trade good for the environment?", American Economic Review, 91(4), pp. 877-908

Asian Development Bank, 1997. Emerging Asia: Changes and Challenges. Manila: Asian Development Bank.

Bandara, J.S. and I. Coxhead, 1999. "Can trade liberalization have environmental benefits in developing countries? A Sri Lankan case study." J. Policy Modeling 21(3). May, pp.349374.

Bhagwati, J., 1978. Anatomy and Consequences of Exchange Control Regimes. Cambridge, Mass.: Ballinger.

Collier, P., and J. W. Gunning, 1994. Trade Shocks: Consequences and Policy Responses in Developing Countries. San Francisco, CA: ICS Press.

Copeland, B.R., and M. S. Taylor, 1999. "Trade, spatial separation and the environment", Journal of International Economics 47: 137-168.

Copeland, B.R., and M. S. Taylor, 2003. Trade and the Environment: Theory and Evidence (Princeton, NJ; Princeton University Press).

Coxhead, I. and S. Jayasuriya, 2003. The Open Economy and the Environment: Development, Trade and Resources in Asia. Cheltenham, UK, and Northampton, MA, USA: Edward Elgar.

Coxhead, I. and S. Jayasuriya, 2004. "Development strategy, poverty and deforestation in the Philippines", Environment and Development Economics, 9(5): 613-644 
Deacon, R., 1995. "Assessing the relationship between government policy and deforestation", Journal of Environmental Economics and Management 28(1), January: pp. 1-18.

Dimaranan, B.; T. Hertel, and W. Martin, 2002. "Potential gains from post-UR trade reform: impacts on developing countries". Paper presented at the International Agricultural Trade Research Consortium meetings, Whistler, British Columbia, Canada: June 16-17.

Gordon, H. S., 1954. "The economic theory of a common-property resource: the fishery", Journal of Political Economy 62(2), April, pp. 124-142.

Jha, R., and J. Whalley, 1999. “The environmental regime in developing countries". NBER Working Papers No. 7305.

Krueger, A. O; M. Schiff, and A. Valdés, 1988. "Agricultural incentives in developing countries: measuring the effect of sectoral and economy-wide policies", World Bank Economic Review 2(3).

Little, I.M.D., T. Scitovsky, and M. Scott, 1970. Industry and Trade in Some Developing Countries: A Comparative Study. London, New York, Oxford U.P. for the OECD.

Lopez, R. and M. Niklitschek, 1991. "Dual economic growth in poor tropical areas", Journal of Development Economics, 36(2), pp 189-211

Matthews, E., 2001. "Understanding the FRA 2000”. Forest Briefing No.1, World Resources Institute, March. Accessed at http://www.wri.org/pdf/fra2000.pdf, March 2002.

Mussa, M., 1979. "The two-sector model in terms of its dual: a geometric exposition”, Journal of International Economics 9, pp. 513-526.

Papageorgiou, D., M. Michaely, and A. M. Choksi., eds., 1991. Liberalizing Foreign Trade. Oxford, UK, and Cambridge, MA: Blackwell. 
Table 1: Estimated changes in natural forest and plantation cover

\begin{tabular}{|c|c|c|c|c|c|c|}
\hline \multirow[t]{2}{*}{ Region } & \multicolumn{2}{|c|}{1990 ('000 ha) } & \multicolumn{2}{|c|}{2000 ('000 ha) } & \multicolumn{2}{|c|}{$\begin{array}{l}\text { Average annual change } \\
\text { of natural forest }\end{array}$} \\
\hline & Nat. forest & Plantation & Nat. forest & Plantation & '000 ha & Per cent \\
\hline Africa & 697,882 & 4,415 & 641,828 & 8,038 & $-5,589$ & -0.8 \\
\hline Oceania & 36,201 & 149 & 34,869 & 263 & -133 & -0.4 \\
\hline S. America & 903,199 & 7,279 & 863,739 & 10,455 & $-3,946$ & -0.4 \\
\hline Asia & 495,340 & 56,117 & 431,422 & 115,873 & $-6,392$ & -1.3 \\
\hline -Tropical & 289,820 & 22,486 & 233,448 & 54,624 & $-5,637$ & -1.9 \\
\hline -Temperate & 205,520 & 33,631 & 197,974 & 61,249 & -755 & -0.4 \\
\hline
\end{tabular}

Source: World Resources Institute calculations from FAO data (Matthews 2001). 
Table 2: Capital-intensity and pollution intensity in Thailand

\begin{tabular}{lcc}
\hline Weighted Average & $\begin{array}{c}\text { Import- } \\
\text { competing }\end{array}$ & Exporting \\
& & -12.01 \\
\hline Effective rate of protection (ERP) & 139.39 & 0.61 \\
$\begin{array}{l}\text { Labor-intensity (labor cost as a } \\
\text { fraction of total cost) }\end{array}$ & 0.42 & 2.92 \\
Acute Human Toxicity Index & 6.47 & \\
\hline
\end{tabular}

Sources: Coxhead (2003 ) 
Table 3: GDP growth rates and shares (\%) of major sectors, selected Asian countries

\begin{tabular}{|c|c|c|c|c|c|c|}
\hline Country & GDP growth & Years & Agric. & Industry & $(M f g)$ & Services \\
\hline \multirow[t]{3}{*}{ Indonesia } & 3.97 & $1960-80$ & 42 & 23 & 10 & 35 \\
\hline & & $1981-90$ & 22 & 37 & 16 & 40 \\
\hline & & 1991-00 & 18 & 43 & 24 & 40 \\
\hline \multirow[t]{3}{*}{ Malaysia } & 4.12 & $1960-80$ & 29 & 30 & 14 & 41 \\
\hline & & $1981-90$ & 20 & 39 & 21 & 41 \\
\hline & & $1991-00$ & 13 & 42 & 27 & 45 \\
\hline \multirow[t]{3}{*}{ Philippines } & 1.04 & $1960-80$ & 28 & 31 & 23 & 41 \\
\hline & & $1981-90$ & 24 & 36 & 25 & 40 \\
\hline & & 1991-00 & 20 & 32 & 23 & 48 \\
\hline \multirow[t]{3}{*}{ Thailand } & 4.34 & $1960-80$ & 29 & 25 & 17 & 46 \\
\hline & & $1981-90$ & 17 & 33 & 24 & 50 \\
\hline & & $1991-00$ & 11 & 39 & 29 & 50 \\
\hline \multirow[t]{3}{*}{ Vietnam } & $5.37^{b}$ & $1960-80$ & & & & \\
\hline & & $1981-90$ & 40 & 29 & 26 & 32 \\
\hline & & 1991-00 & 29 & 30 & 20 & 41 \\
\hline \multirow[t]{3}{*}{ Sri Lanka } & 2.99 & $1960-80$ & 30 & 24 & 17 & 47 \\
\hline & & $1981-90$ & 27 & 27 & 15 & 46 \\
\hline & & $1991-00$ & 23 & 26 & 16 & 50 \\
\hline
\end{tabular}

a. Real per capita income (1995 US\$), annual average 1970-2000. b. 1991-2000. .. = not available. Source: World Bank: World Development Indicators 2001 
31

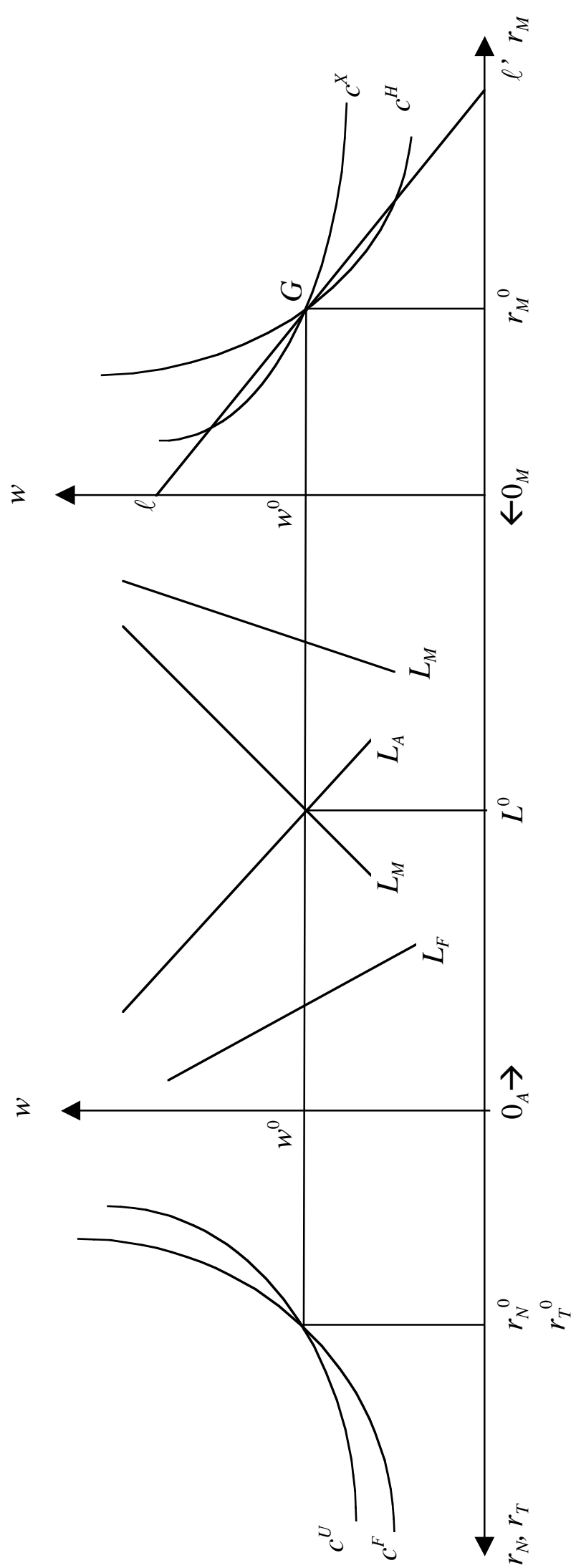

e)
0
0
0

$\begin{array}{ll}2 & \sqrt{2} \\ 0 & 0 \\ 0 & 0 \\ 0 & 0\end{array}$

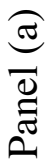




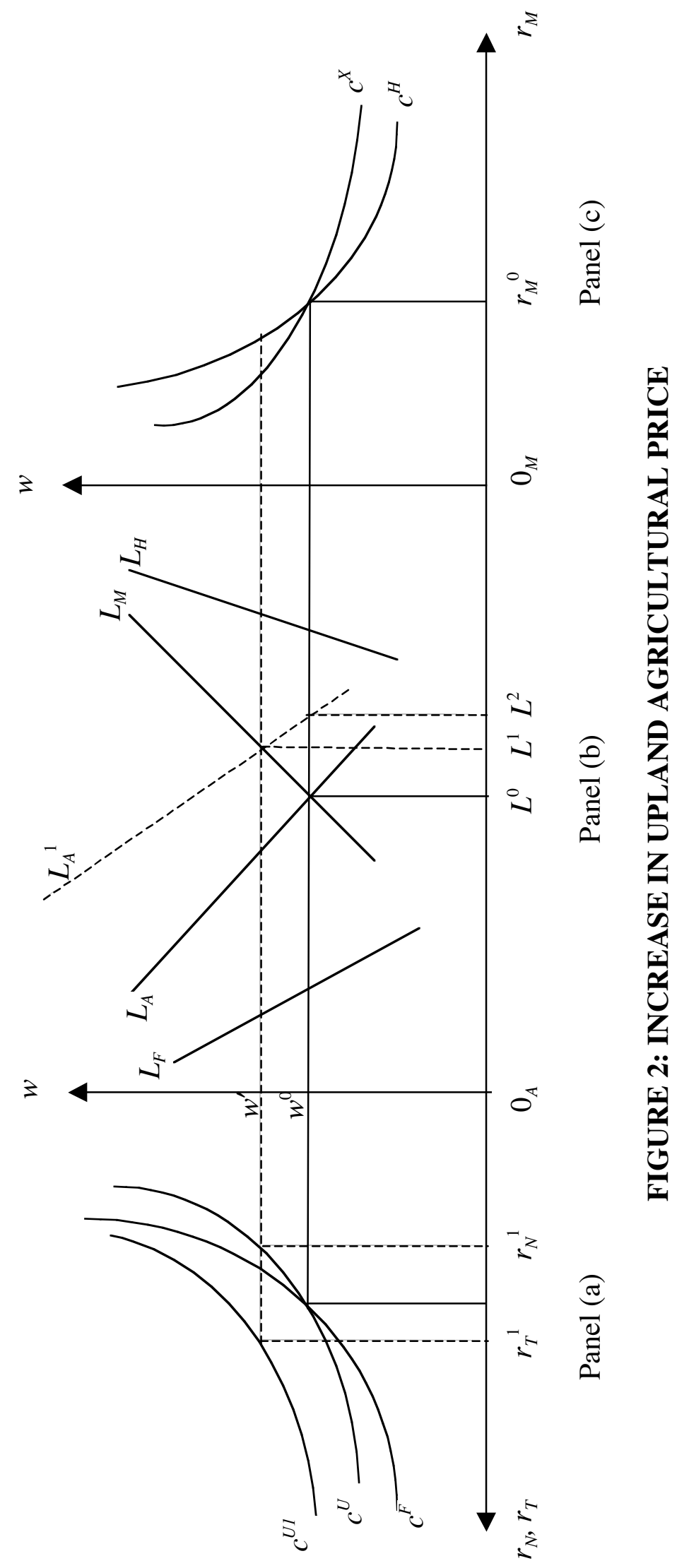




\section{Notes}

1 "One large omission from our review is any explicit discussion of renewable or nonrenewable use of resource use or sustainability... but an analysis of trade's impact on resource use will take us too far afield". (Copeland and Taylor, 2003:5).

2 The model is a major revision of Coxhead and Jayasuriya (2003). Some features, notably the modeling of forest clearing in upland, are drawn from Lopez and Niklitschek (1991). 3 This assumption is easily changed to reverse comparative advantage in the two crops, and also to permit a single commodity to be produced in both areas but with different levels of land productivity.

${ }^{4}$ The spatial separation of upland and lowland can be exploited to yield richer model specifications that generate insights into impact of enhanced domestic market integration in previously segmented labor and goods markets.

${ }^{5}$ Our key point is that any reduction of virgin forest leads to environmental losses. We do not seek to address the widely analyzed case of the impact of higher timber prices on forests, where commercial forests are included as part of the total forest endowment.

6 This can be easily relaxed; see Copeland and Taylor (1999). Coxhead and Jayasuriya (2003) also explore intersectoral production externalities in a similar model.

${ }^{7}$ The positive externalities associated with trade liberalization are often highlighted in the literature. In principle, however, trade liberalization in capital/skill intensive manufacturing may also imply foregoing positive externalities associated with 'learning by doing' type effects. 
${ }^{8}$ This assumption is made for convenience only. Coxhead and Jayasuriya (2003) model upland production with more than one output and different factor proportions.

${ }^{9}$ If there were non-traded final goods in the economy, there would be additional substitution terms in (6) due to endogenous price changes (Coxhead and Jayasuriya 2003).

${ }^{10}$ Nor are the costs of forest clearing limited to the national economy. In Indonesia, widespread forest burning to establish oil palm and other plantations since the late 1990s has generated significant pollution in the form of smoke, or 'haze' in neighboring countries as well as through much of Indonesia itself.

${ }^{11}$ Output in each of the $M$ sectors can also be computed from the diagram, by drawing lines tangential to each unit cost curve at the point of intersection and calculating sectoral employment shares of capital and labor along each axis. See Mussa (1979).

${ }^{12}$ In countries with diversified upland sectors - producing both food and export crops - tariff reduction will have an unambiguously pro-forest effect, if plantation crops grown in uplands are less land-intensive and do not produce other forms of environmental damage (see Coxhead and Jayasuriya 2003).

${ }^{13}$ See Coxhead and Jayasuriya (2004) for a discussion of the Philippines case.

${ }^{14}$ Such extensions can draw on Copeland and Taylor (1999) who present a model in which industrial emissions degrade the natural resource base, and Bandara and Coxhead (1999) who analyze the effects of soil erosion on industrial production costs through impacts on hydro power production. 